\title{
Aubrey Lewis's Introduction to his Report
}

At the suggestion and with the support of the Rockefeller Foundation I visited in 1937 all the European countries except the Balkans, Spain and Portugal, and Germany. As I had already seen something of the psychiatric work in Spain before the Civil War, and had studied in Germany some years ago, when the level of medical work there was higher than it is at present, these omissions did not appreciably affect the purpose of my journey, which was to learn what is being done in neuropsychiatry and related fields. The net was cast fairly wide, in that I was provided by the foundation with letters of introduction not only to those active in teaching and research in neurology or psychiatry, but also to the physiologists, psychologists, geneticists, and others who were pursuing in these fundamental sciences studies which would throw light on our clinical problems and methods of investigation; I was also able to see administrators who controlled organization and development.

Such a round of visits (formidable in many respects, and quite impracticable if one had not already from the literature and from personal contacts some knowledge of the work being done) was a reminder of the enormous field psychiatry now straddles over or touches; from social legislation, psychotherapy, or statistics, to neurology, internal medicine, and the minutiae of laboratory research.

I have put down in order the men and places I visited, and stated at the beginning some general impressions. It would be possible to avoid so bald a catalogue of an immensely informative and stimulating journey by giving a much more detailed account, which would be to a large extent technical, and by expressing freely the opinions I formed about what I saw in each place, but these, in the circumstances, might sound patronising when appreciative, and hasty or ill-mannered when critical. Moreover, it was impossible not to see the close influence which the political and social situation in each country had upon psychiatry, whether as a branch of public health, medical practice, or research (this, however, goes rather beyond what were my immediate "terms of reference"). It was evident - perhaps as a by-product of this state of affairs - that in many places where Germany had long been regarded as the European seat of authority and progress in medical, and especially psychiatric, matters, its place was being taken by England and USA. Many people, I found, were eager to turn to our journals and to get into contact with the men in our centres of activity. Their familiarity with the teaching and research institutions here was far greater than used to be the case. The National Hospital at Queen Square has, of course, long been famous, but I found that the Maudsley Hospital, too, was known in a way that seemed, in view of the recency of its foundation, remarkable.

So comprehensive a round of visits naturally yielded much that is difficult to summarize; its fruits were mainly of two kinds - those more immediately applicable to 


\section{Aubrey Lewis}

one's work, e.g. fresh knowledge and ideas for treatment, research, etc.; and less precise general impressions, chiefly about trends and methods which might be compared with those at home.

It was everywhere being recognised that psychiatry was a far more important branch of medicine than had generally been realised and that its two great needs were research and better organisation (the latter in the largest sense). In all the places I visited, the main or only centre for research and teaching was the university clinic, but at Dikemark and some other mental hospitals important research or treatment was being done independently; nearly always this was due either to one enterprising and able doctor who had sufficient control of the administration of a hospital to carry through his plans, or to the influence of someone at the university. The problems of the mental hospitals were necessarily of a different order from those of the university clinics; in many places where they were represented as largely economic it seemed that, even if this were true, better training of nurses and use of occupational measures might have disposed of some of the difficulties in the proper care and treatment of the patients. In some countries the institutional and extra-mural treatment of the insane was on an admirably high a level, so far as I could observe or learn of it. The standards of selection, recruitment, and training of nurses varied widely, and, like those of medical and social worker personnel, of course depended to a considerable extent on the general economic and cultural conditions of the country, but to this there were some striking exceptions.

In the university clinics neurology and psychiatry were, as a rule, a combined discipline under the one professor. Sometimes this had tended to disproportionate emphasis being laid on one or the other, according to the professor's special interests. Even those who, on account of this, advocated separate departments conceded, however, that a purely psychiatric or purely neurological clinic led to an artificial, regrettable limitation of interest and outlook.

The concentration of research and teaching in the university clinics - to which it is true, there is an occasional outstanding exception, as at Dikemark - is so much the rule abroad that the professor in charge usually has his hands full of this work, and consequently exercises a general rather than a detailed supervision over administrative routine, much as in American clinics. In principle he is in charge of all such matters, though the extent to which he has actually the final say within the clinic sometimes depends on whether immediate political influence is brought to bear on the internal work of the clinic, as was evident in Russia, for instance, and Austria. One cannot generalise about it. Usually, however, the day-to-day administration is delegated to the Oberarzt, Chef de Clinic, or similarly named position, by the professor, so that he can himself devote his time to teaching and research. Economic necessity, moreover, may lead to encroachments on his time in the form of private practice. Conditions cannot very well be compared with those prevailing in England, since in nearly all these countries no one who is unconnected with the university clinic is likely to have much standing as a consultant in private practice, and on the other hand the clinic cannot pay an appropriate living wage to its doctors. Consequently the senior staff of the university clinics is mostly on a part-time basis and is made up of the active leaders of the speciality. Moreover, the prestige attaching to a position in the clinic is 
so advantageous in private practice that there is great inducement for people to work in the out-patient departments and elsewhere for a small salary. Entirely honorary work is, however, rare because of the exigencies of earning a living. In all these respects psychiatry is organised in the university clinics on the same lines as are followed in other departments of medicine. The effort is everywhere to make these clinics a part of the single university hospital, (the mental hospitals being seen as the future field of work for those trainees of the university clinics who do not propose to go into private practice). Thus, in Denmark all appointments to a mental hospital superintendency go to the staff of the university clinic: this has the apparent disadvantage that the Professor is almost the only permanent member of the senior staff there, and the continuity of research is in danger. The links between the other medical clinics and the psychiatric one are strengthened by the growing practice of seconding men from the latter to work for a year in laboratories of physiology or internal medicine, and, on the other hand, as in Amsterdam, putting men trained in internal medicine into the psychiatric hospitals, not so much to learn psychiatry as to deal expertly with the physical problems, and promote research and treatment along these lines.

A great deal of the most promising research that was being done consisted in the application to clinical psychiatry of methods that had been worked out in other fields, for example, sociology, biochemistry, internal medicine, physiology, genetics. It followed that the best research of this kind was done by collaboration rather than by psychiatrists alone attempting to employ the methods and ideas with which they had become acquainted only by reading, instead of by training. Occasionally, of course, brilliant work was being done by men who had set themselves to acquire an adequate training in both psychiatry and the relevant science. On the whole, it was in places where collaboration between the various departments of the university and the psychiatrists was best developed that the most valuable psychiatric research was being done. The more isolated the psychiatrists, the more likely was their research to be humdrum or unreliable. On the other hand, in a few places research and psychiatry was being done, mainly on laboratory lines, by men who had not any thorough acquaintance with clinical psychiatry; in such cases their research seemed often to be departing from rather than approaching problems of psychiatry, sometimes confusing issues or leading them in deeper shadow through ignorance of the many sided phenomena of mental disorder and the fallacies and real questions they may give rise to. Where research was being directed by a half-time psychiatrist who was engaged in private practice it tended to be hand to mouth, uncritical, or unduly influenced by fashions of the moment and practical exigencies; in short, bulky rather than valuable.

The need for specialization within the psychiatric field is well recognised. Where it can be afforded, there are men separately concerned with the psychological, social, physiological, biochemical, psychotherapeutic, and other divisions of the work. The Professor and some other senior men serve to co-ordinate all this, whether in treatment, research, or teaching. In different countries or different centres the emphasis falls on this or that department, naturally, according to prevailing interests. It was noteworthy that hardly anywhere had psychoanalysis established itself as an acceptable theory or practice, incorporated in the general body of psychiatry. Its influence in stimulating the development of psychological treatment and dynamic psychological modes of approach 


\section{Aubrey Lewis}

had obviously been great, but general acceptance of the fundamentals of psychoanalytic doctrine seemed now to be less likely than it was, perhaps, some years ago, and its use as a mode of treatment seemed very restricted.

In nearly all countries the financial deterrents to entering on a career of research seemed to be a hindrance in the development of psychiatry. Those who go into private practice, as the majority must, are forced in the richer countries to direct their interests largely into psychotherapy, without being able to study its problems dispassionately, and in the poorer ones to aim at some prestige-giving academic status which may be less of a by-product of ability and enthusiasm than a means towards earning a living. Nevertheless, academic status (e.g. having spent some years in a university clinic, teaching) and a record of having done conscientious research have so much more to do with any advancement in a psychiatric or other medical a career abroad than they have in England that the general level of training and experience in what may recall the hack-work of research - making a prescribed investigation painstakingly or at any rate industriously, working through the literature of a problem and summarising it with discrimination, using advice and criticism and learning one's limitations - was higher among the general run of psychiatric aspirants than it is with us. Particularly in Scandinavian countries the rigorous demands of the MD qualification raised the standard of work in the university clinics and institutes, and indirectly throughout the country. I find it difficult to generalise, however, because of the enormous differences between countries, e.g. between Hungary and Holland; Sweden and Czechoslovakia; or even adjacent ones like Russia, Poland, and Finland. Political factors and jobbery were, however, rapidly altering the state of affairs in the dictator or semi-dictator ruled countries: clearly the future professors and hospital directors were going to "get by" with less to their scientific credit than their predecessors had to show.

In some countries there was a contrast between their impressive buildings and laboratory equipment on the one hand, and, on the other, the low standard of hospital care and of social concern or provision for the patients who were outside an institution. In short, all that in England or the United States is linked up with the psychiatric nurse and the social worker seemed to call for much improvement in some of the countries I visited. In some places the predominance of neurology and the extravagances of some psychotherapists seem to have had almost an equal share in delaying the development of the social and psychological side of psychiatry. There were, in addition, political and economic factors to which I have already referred. There was, in part, the tendency in totalitarian countries to reward spectacular work, whether sound and not, also to promote party men, to damp down scientific criticism, and to hamper or exclude some able people who should have had influential positions and good opportunities to work; even, sometimes, to modify a theory for irrelevant reasons (e.g. in genetics of insanity and defect, value of psychological measurements, aetiology of neuroses). An indirect and less obvious effect, though a real one, was the personal distress and unhappiness, apart from any material difficulties of their own, that some of the best productive workers feel while living under tyranny or a threat, so that they cannot pursue their work with a free and single mind. In all countries individual economic problems, of course, troubled research workers and practitioners. 


\section{Introduction to Report}

One of the commonest developments in psychiatry in the various countries was the establishment of clinics for children. In the less advanced places there were the very simple beginnings of a special out-patient department at which abnormalities of behaviour in children could be hastily investigated and treated: in a few places, it is true, they went no further than still unrealised plans, but hardly any university clinic had failed to recognise the necessity for having such a department. In the most advanced centres there was a thoroughly organised, well staffed out-patient department, run on much the same lines as those established in Great Britain and the United States; moreover, in some instances, a separate residential block had been provided for the observation and treatment of a small number of children for a limited period. These residential blocks were almost exclusively to be found in Switzerland, where in spite of such disadvantages as, in some cases, that of being situated in the grounds of the mental hospital, their value was recognised not only by the psychiatrists but by the administrators and the public of the canton. The importance of research, as apart from treatment, in the social, psychological, and somatic aspects of children's behaviour and maladaptations was everywhere strongly felt, but the investigators were also well aware of the limits set to their work by the necessarily unsatisfactory and incomplete opportunities that purely out-patient work can offer. Even in the few places where this deficiency was being supplied by an in-patient block the arrangements and the work done were so influenced by immediate practical needs (e.g. for the supervision of delinquent children) that the full possibilities and requirements for sound continuous work were scarcely anywhere being met. Certainly there was nothing being done for children that compared with what is available for adults whose behaviour is abnormal.

The work with children had partly arisen out of social needs: juvenile courts, for example, wanted the psychiatrist's advice. In some countries the more extensive social side of psychiatry, with adults as well as children, had received much attention. Thus, in Belgium the Law of Social Defence has stimulated, or perhaps one should say is evidence of, the great concern in that country with social problems where they touch on medicine, and particularly on psychiatry: the control of delinquency, alcoholism, etc., is recognised to be a field in which psychiatry has much to say. In Switzerland much of the social psychiatric work that would be done only sporadically in England is in some cantons regularly referred to the psychiatrist: in Zürich, for example, he writes regular reports on all women whom the gynaecologists at the general hospital are considering for abortion or sterilisation. In Scandinavian countries, France, Russia, and elsewhere, the social side of psychiatry is being increasingly organised, though there is obviously still much to be done. There was also a good deal of anxiety, I found, lest over-enthusiastic or half-baked work in this field should prejudice sound development. Consequently, independent efforts at dealing with the psychiatric side of delinquency, feeble-mindedness, prostitution, incapacity for employment, etc., were thought far less satisfactory than the referral of such matters to the psychiatric clinic or to reliable and well-trained psychiatrists who had been on the staff of the clinic. In Sweden Prof Kinberg had his own department for examining criminals, working directly under the Ministry of Justice: Dr Schiff similarly in Paris, and Prof Vervaeck in Brussels. 


\section{Aubrey Lewis}

In several places there was a growing tendency towards making the expert facilities and knowledge of the university clinic available to the less indigent members of the community. This was partly due to obvious pressure, based on economic and social grounds, from the side of the public, who were contributing to the maintenance of these centres, and could not see why their enjoyment of the advantages so provided should be in inverse proportion to the amount they contributed towards their upkeep. In Scandinavian countries, in particular, this line of development has gone far, and I was able, as a patient myself in the private medical wards of the great Rigshospital in Copenhagen, ${ }^{1}$ to see how much the patient gains by being treated in a public hospital fully-equipped for teaching and research. I was told however, by responsible administrators in the Government ministries, as well as in the psychiatric hospitals, that for the hospitals themselves the economic side of the matter is far from negligible since the fees received from private patients (though the charges are remarkably low in Scandinavia) are an important item in the budget. This matter was particularly stressed, from a different angle, at the neuro-surgical unit in Warsaw. Since the only fully-trained brain surgeon in Poland works there on a full-time basis, all, whether rich or poor, must become patients there if they want the best attention available in their country: but it is a public hospital which has a low fixed upper level of fees and will not charge well-to-do people in proportion to their income. The available money for the upkeep of the unit is very little, and the surgeon in question has to do as best he can with quite inadequate medical and nursing help. He deplores this, and, since he cannot get from the public authorities more money for staffing the unit on modern lines, he considers that it would be better to have a private department with corresponding fees, or else to allow him private practice, so that the money he thus earned from wealthy patients might be diverted to the staffing, etc., of the public unit, and to the financing of his research, which is at present hampered by lack of funds. In other places I was told that a private block in the public psychiatric clinic or hospital had had the advantage that the nurses and doctors, working, as they do, sometimes there and sometimes in the rest of the hospital, were found to be still more likely than ordinarily to have a friendly and individual attitude towards the needs of their patients, avoiding the impersonal or custodial attitude. I had no chance to judge what evidence there was for this belief. It certainly seemed to me that the situation of a psychiatric clinic as one of the separate departments in a complex of hospital buildings (with public and private wards), which made up the whole university teaching centre in medicine, was admirable for the training of nurses: Amsterdam and Copenhagen were conspicuous examples of this. Independent neuropsychiatric clinics seemed also in certain centres to provide equally good training, e.g. in Belgium. But the training of nurses depends so much on local conditions but it would seem idle to make too much of hospital layout and type of patient in this regard.

The level of psychiatric work in many of the places I visited could almost have been measured by the way they were pursuing and assessing the newer treatments, i.e. insulin and cardiazol for schizophrenia. In some, work was being well done, and its range extended on sound lines, but in many, little clinical acumen or ability in

\footnotetext{
${ }^{1}$ While in Uppsala in September 1937, Lewis fractured his radius and also contracted pleurisy. As a consequence, he stayed in hospital for two and a half months before returning to England in December.
} 


\section{Introduction to Report}

planning and evaluating such a therapeutic experiment was being displayed, and the research possibilities were being neglected.

There is no single line of research in psychiatry which at the time of my visit appeared to be leading to a dramatic advance in the subject; there was an attack along a wide front, as the details of my various visits will have shown. The most impressive advance, taking the various European countries as a whole, seemed to be in the effort to improve institutional care, along the lines that are the recognised in England and other countries with a similarly highly developed social and medical system, as well as to provide adequate treatment and supervision for those whose mental disorder is not such as to demand in-patient care. So various, however, were the conditions and methods I observed that any general statement is in danger of giving a false impression. 